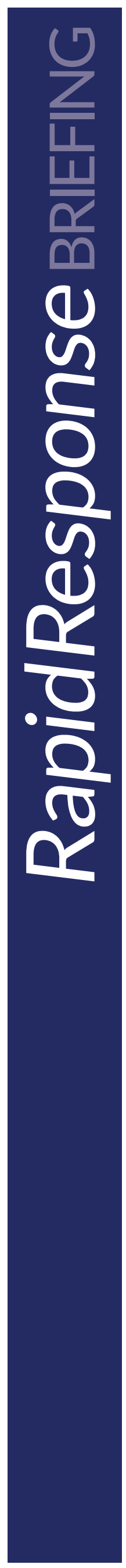

Issue $1 \bullet$ July 2017

\title{
Automation, Women, and the Future of Work
}

Will women benefit from the rapid automation and digitisation that is set to change the world of work as we know it? How can we ensure that women's economic interests are brought into focus, and that debates on the future of work are not about the changing relationship between man and machine, but between people and machine? This briefing explores the impact of automation on women and work in developing countries, considering global targets on valuing unpaid care, rights to economic resources, and access and use of information and communication technologies.

\section{Decent work for all in an age of automation}

The eighth Sustainable Development Goal (SDG), adopted by the global community in 2015 , calls for productive employment and decent work for all by 2030 . But how will this Goal be achieved in a rapidly digitising world, where the majority of jobs are likely to be lost to automation? Recent research predicts that 47 per cent of jobs in the United States, 85 per cent of jobs in Ethiopia and 77 per cent of

\section{Gender, work, and automation}

Research shows that men and women will not equally experience job losses due to automation. Overall, men stand to gain one job for every three jobs lost to technological advances, while women are expected to gain one job for every five or more jobs lost. On the other hand, as social skills are particularly important in high-paying jobs that are difficult to automate, the shift in women's employment towards social skillintensive occupations may mean women actually benefit from automation. Research from the United States shows that the three occupations expected to grow the most between 2014 and 2024 are personal care aides, registered nurses and home health aides.

Much of the debate on the future of jobs has focused on the formal sector, with little attention paid to the impacts of automation on the two billion jobs in China are at risk of automation in the coming years. Research from the Institute of Development Studies for the 2017 Digital Development Summit found that governments, businesses and global institutions are not prepared for such large-scale, rapid change, and are failing to put in place anticipatory and adaptive measures to cope with its impact.

working-age adults classified as being outside of the workforce - many of whom are women.

The broader framing of debates on automation inevitably reflects deeply embedded sexism in society. For example, why is Amazon's virtual artificial intelligence assistant, Alexa, female? What will be the impact of such sexualised robots on the objectification of real women and girls? Research has shown that sexism is 'hard-wired' into the online systems we use every day. For example, gender stereotypes are encoded into algorithms by associating certain professions with particular genders: receptionists and nannies are female, while architects and philosophers are male. Overall, these issues reflect broader structural inequalities experienced by women in employment (see Box 1). 


\section{Box 1: Gender inequalities in employment}

- Income: Globally, women's earnings are 77 per cent of men's, with the gap widening for higher-earning women (International Labour Organization 2017)

- Pay equity: Without targeted action, pay equity between women and men will not be achieved before 2086 (International Labour Organization 2015)

- Participation: The global labour force participation rate for women stands at 49 per cent, nearly 27 percentage points lower than the rate for men (International Labour Organization 2017)

- Geography: The largest gender gap in participation rates (31 percentage points) is faced by women in emerging economies such as Brazil, Indonesia, South Africa and Turkey (International Labour Organization 2017)

- Quality: In emerging economies, female workers are typically employed in less-productive and lower-paid sectors, their jobs are more insecure and they are at higher risk of extreme low pay than men (Organisation for Economic Co-operation and Development 2016)

\section{How will automation impact on decent work for all?}

Against this backdrop, it is clear that the achievement of SDG 8 by 2030 will be impossible without considering the risks and benefits of digital technology and automation. But this in turn will be unachievable without paying attention to gender in line with SDG 5: 'achieve gender equality and empower all women and girls'. This briefing explores the impact of automation on three of the targets under SDG 5, recommending how governments, businesses, civil society and others can ensure gender is properly considered in debates on the future of work.

\section{Value unpaid care work}

SDG Target 5.4: Recognise and value unpaid care and domestic work

Care work is a key contributor to women's lack of economic empowerment. Women endure the disproportionate burden of unpaid care work at home, and also experience low wages for paid employment in the care economy. IDS research by Deepta Chopra has demonstrated a strong inverse link between the amount of time that women and girls spend on unpaid care work and their economic empowerment. Many women face a double burden of time poverty through discrimination in the labour market and also in the drudgery that is found in domestic responsibilities. Women also face significant barriers in accessing formal employment, such as the high transport and time costs associated with travelling to formal sector jobs that are often only found in large cities.

Care work often appears in debates about automation in terms of the potential for humanoid robots to be used as personal assistants and companions. Yet is it desirable or even ethical for care to be automated? Caring labour is typically devalued, but it also offers its own emotional rewards as people derive pleasure from the wellbeing of others. While robots may soon be able

\section{Work towards equal access to economic resources} SDG Target 5.7: Undertake reforms to give women equal rights to economic resources

The International Monetary Fund estimates that 865 million women worldwide have the potential to contribute more to their economies, and 94 per cent of these women live in developing countries. In many countries, distortions and discrimination in the labour marketrestrictwomen'soptionsforpaidwork. Research shows that when womentry to overcome thesebarriers by starting their own businesses, many face obstacles: to look after elderly people - taking on work that is currently typically performed by poorly remunerated women - is this what society wants? Robotic systems cannot offer empathy or shared experiences. The Engineering and Physical Sciences Research Council's (EPSRC) Principles of Robotics warns that robots must be regulated in a way that ensures they do not exploit vulnerable users. As automation develops, social science researchers must engage with these principles and consider ways to quantify and explain the impacts of these changes to a broader population.

Rather than seeking to automate the burden of care, policymakers and governments should instead be looking to redistribute the burden of unpaid care work from poor families to the state through provision of public services, infrastructure and care-sensitive social protection. In recognition of this, the International Labour Organization (ILO) callsfor decent work for care professionals, including domestic and migrant workers. 
The concept of a Universal Basic Income (UBI) - a flat rate salary distributed to all citizens has become increasingly popular as a means to mitigate the impacts of automation on employment. UBI proponents suggest income security could lead to people spending more time on things they actually care about and improving society, and thus see an increase in creativity and innovation. How to make UBI work is likely to vary in different contexts, but a recent study on the impact of a UBI trial in India showed that such a scheme had a positive impact on women's economic citizenship. Women were not only able to increase and diversify their economic roles and acquire assets, but they also experienced an increase in critical consciousness and empowerment.

Without forms of social protection such as the UBI, it is likely that women in developing countries will suffer more from the impacts of automation as their jobs come under threat and they are less likely to be able to find alternative sources of employment. In recent years, for example, in countries such as the Philippines, the business process outsourcing (BPO) industry has flourished, delivering services such as back-office support, animation, software development and data transcription. This sector has been an area where women have had an opportunity for economic advancement, accounting for 59 per cent of the workforce. But research has shown that many of these jobs are at risk from automation - for example, 89 per cent of salaried call centre staff in the
Philippines BPO sector are at high risk of job losses. A recent ILO report on the workforce in Cambodia, the Philippines, Vietnam, Thailand and Indonesia found that workers in the garment manufacturing industry are especially vulnerable to displacement by robots. Many businesses hope automation will deliver the same work at a higher standard, without the human cost. In some Southeast Asian countries, more than 70 per cent of workers in the textile, clothing and footwear industries are women. ESRC-DFID-funded research on sweatshop regimes in the garment industry shows the degrading conditions in which women work:

Supervisors are generally men, and many women workers report gender-based harassment as a key problem. Male supervisors often deploy abusive comments to discipline workers and remind them of production targets. Many may also engage in physical touching or degrading practices, such as appealing to sexual visual imagery when talking to their 'subordinates' on the shop floor. Indeed, the factory reproduces the same structures of oppression women often face in their private sphere.

In this instance, it might be possible to argue that women could benefit from automation - if many garment manufacturing jobs are replaced by robots, women will no longer have to work in these poor conditions. But this will only be the case if the right mitigation strategies are put in place to protect women's livelihoods.

\section{Promote women's empowerment through digital skills}

SDG Target 5.8: Enhance the use of enabling technology, in particular information and communications technology, to promote the empowerment of women

The examples above powerfully illustrate the potential negative impact of digitisation on women's economic status in developing countries. Without digital skills women are unlikely to benefit from the more senior technological jobs that will remain available when the bulk of BPO jobs are automated. But while research shows there has been a rapid increase in women working in the IT industry in India and other BRICS (Brazil, Russia, India, China and South Africa) countries, these women progress more slowly than their male colleagues.

There is a significant gender gap in terms of women's access to digital tools. Globally, women are on average 14 per cent less likely to own a mobile phone than men, and poor urban women are about 50 per cent less likely to have access to the internet than men. The Web Foundation has called for a range of policy interventions including prioritising investment in digitising the information and services that low-incomewomen will find most valuable and ensuring a public fund for technology development (such as subsidies or incentives for technological entrepreneurs) is specifically set aside for projects led by women. Policy outputs on the impact of information and communication technologies (ICTs) in developing countries often promise a causal link between internet connectivity and economic growth, which is arguably implicit in this SDG target. These claims are scrutinised in ESRCfunded research on economic development and broadband in East Africa, finding that the current evidence base is mixed and inconclusive. It is therefore essential that the organisations who make these promises are asked to justify their claims, rather than assuming it is self-evident that ICTs will automatically bring about development. The researchers found that all policies assume, without explicit evidence, that through ICTs women are able to access information and participate in the economy, society, and politics.

Further ESRC-funded research on the impact of mobile phones on young people's lives and life chances in sub-Saharan Africa, highlighted how mobile phones contributed to youth livelihood strategies, such as through job search, micro-enterprise and providing a 
safety net. The research finds that while many young people use mobile phones in their search for work, they are not enough to overcome structural inequalities. Low levels of education, increasing competition for jobs and little opportunities for work experience exacerbate unemployment. According to lead researcher Gina Porter: 'unless the overall basket of opportunities grows, mobile phones are not going to be the answer.' In a similar way, structural inequalities faced by women and girls must be overcome if mobile technology is to promote women's empowerment. The research also found that girls experienced bullying from boys or older men on their

\section{Recommendations}

This briefing shows that the impact of automation on women is critically important in the achievement of the global goal of decent work for all by 2030. It has demonstrated that this goal is interlinked with other SDG targets on gender equality in employment, economic opportunity, care work and access to technology. With such a rapid pace of anticipated technological change, tackling these issues is all the more urgent.

To promote decent work for all - including women - by 2030 , the following recommendations must be implemented:

\section{Researchers and analysts}

- Researchers must urgently create cross-cutting partnerships across disciplines, geographies and sectors, which address automation's impact on women in developing countries.

- The research community can help broker coordinated, multi-stakeholder responses to the future potential impacts of automation.

- Researchers must ensure that future research agendas take account of women's experiences and voices.

\section{Civil society and advocacy organisations}

- Gender-focused advocacy on digital issues must expand, ensuring women can enjoy their right to use digital tools for economic and social empowerment without fear of harassment.

- Global advocacy is needed on automation as a critical global development challenge, making links with issues such as unpaid care work.

- NGOs can provide a frontline 'early warning' function to explore the diverse impacts of automation on different groups in developing countries.

\section{Policymakers}

- Policy shifts are needed at a national, regional and global level to ensure digital education opportunities are available to girls, with a focus on lifelong learning.

- Donors and other policymakers must address digital inequalities in their activities to promote women's economic advancement.

- Serious consideration needs to be given to shifts in working practices (such as shorter working weeks) which have the potential to not only address automation-related job losses, but also benefit women with caring responsibilities.

This series of Rapid Response Briefings is brought to you by The Impact Initiative for International Development Research. The Initiative exists to increase the uptake and impact of two programmes of research funded through the ESRC-DFID Strategic Partnership. To subscribe: www.ids.ac.uk/idsrapidresponsebriefings

\section{THE IMPACT INITIATIVE}

For International Development Research

\section{Further reading}

Faith, B.; Hernandez, K. and Ramalingam, B. (2017) Background Paper for the Digital Development Summit 2017

Friederici, N.; Ojanperä, S. and Graham, M. (2016) The Impact of Connectivity in Africa: Grand Visions and the Mirage of Inclusive Digital Development, SSRN Scholarly Paper 2855398, Rochester NY: Social Science Research Network International Labour Office (2015) Women and the Future of Work: Beijing + 20 and Beyond, Geneva: Gender, Equality and Diversity Branch, ILO

Mezzadri, A. (2016) 'Class, Gender and the Sweatshop: On the Nexus between Labour Commodification and Exploitation', Third World Quarterly 37: 1877-1900

Porter, G.; Hampshire, K.; Milner, J.; Munthali, A.; Robson, E. et al. (2016) 'Mobile Phones and Education in SubSaharan Africa: From Youth Practice to Public Policy', Journal of International Development 28: 22-39

\section{Credits}

This Rapid Response Briefing was written by Becky Faith and reviewed by Pauline Oosterhoff, Institute of Development Studies. Further editing was provided by Sarah Nelson and Kelly Shephard.

The material has been funded by the Economic and Social Research Council and UK aid from the UK Government. However, the views expressed do not necessarily reflect the official policies of the UK Government or ESRC.

Readers are encouraged to quote and reproduce material from issues of Rapid Response Briefings in their own publication. In return, IDS requests due acknowledgement and quotes to be referenced as above.

(C) Institute of Development Studies, 2017 